Cerebrovasc Dis 2011;31:414-415

DOI: $\underline{10.1159 / 000323611}$

\section{Early Repolarisation Syndrome and Ischemic Stroke: Is There a Link?}

\author{
Bernd Kallmünzer ${ }^{a}$, Joji Kuramatsu ${ }^{a}$, Lorenz Breuer ${ }^{a}$, \\ Tobias Engelhorn ${ }^{b}$, Martin Köhrmann ${ }^{a}$
}

Departments of a Neurology and ${ }^{b}$ Neuroradiology, University Medical Center Erlangen, Erlangen, Germany

\section{Case Report}

The emergency service found a 36-year-old man lying outside awake but nonresponsive on the ground. The symptoms had occurred more than $12 \mathrm{~h}$ earlier during a training run and the patient was hypothermic $\left(35^{\circ} \mathrm{C}\right)$ but in stable cardiorespiratory condition. Neurological examination revealed a global aphasia and a high-grade hemiparesis of the right side. The patient was an ambitious sportsman of athletic physical constitution, had an unre- markable medical history and did not take any medication. Emergent MRI demonstrated subacute extensive infarction in the left middle cerebral artery (MCA) and anterior cerebral artery (ACA) territories with proximal occlusion of both vessels. $\mathrm{T}_{1}$-weighted fat suppression sequences did not reveal any evidence for a dissection of extra- or intracranial arteries at baseline and in a repeated MRI examination after 5 days. Extracranial sonography was unremarkable and without arteriosclerotic changes; laboratory values, including a broad workup for thrombophilia and autoimmunity, showed no abnormalities. Transthoracic and transesophageal echocardiography excluded structural heart disease or valvular pathology, and no intracardial thrombi were detected. However, the patient was found to have a persistent foramen ovale measuring $1.4 \times 0.3 \mathrm{~cm}$ in diameter without septal aneurysm. Deep venous thrombosis of the legs was excluded by ultrasound and the D-dimers were within normal limits on the second day after admission $(<500 \mathrm{ng} / \mathrm{ml})$. The ECG at baseline was unremarkable with regard to rhythm (sinus rhythm), heart rate (90/ $\mathrm{min}$ ), heart axis $\left(55^{\circ}\right)$ and conduction times (PQ $178 \mathrm{~ms}$, QRS 96 $\mathrm{ms}$, QT $398 \mathrm{~ms})$. However, early repolarization pattern (ER) of the
Fig. 1. a Follow-up MRI on day 4 demonstrating extensive MCA infarction involving the left insular cortex as well as ACA infarction (lower picture). b ECG at baseline shows ER with notching at the end of the QRS complex in the 3 inferior leads (II, III, aVF). c At the follow-up ECG 10 days later, ER changes were limited to leads III and aVF, had decreased in amplitude and changed the morphological pattern from notching to slurring. Arrows indicate ER. Heart rate at baseline: $90 / \mathrm{min}$, at followup: $50 / \mathrm{min}$.

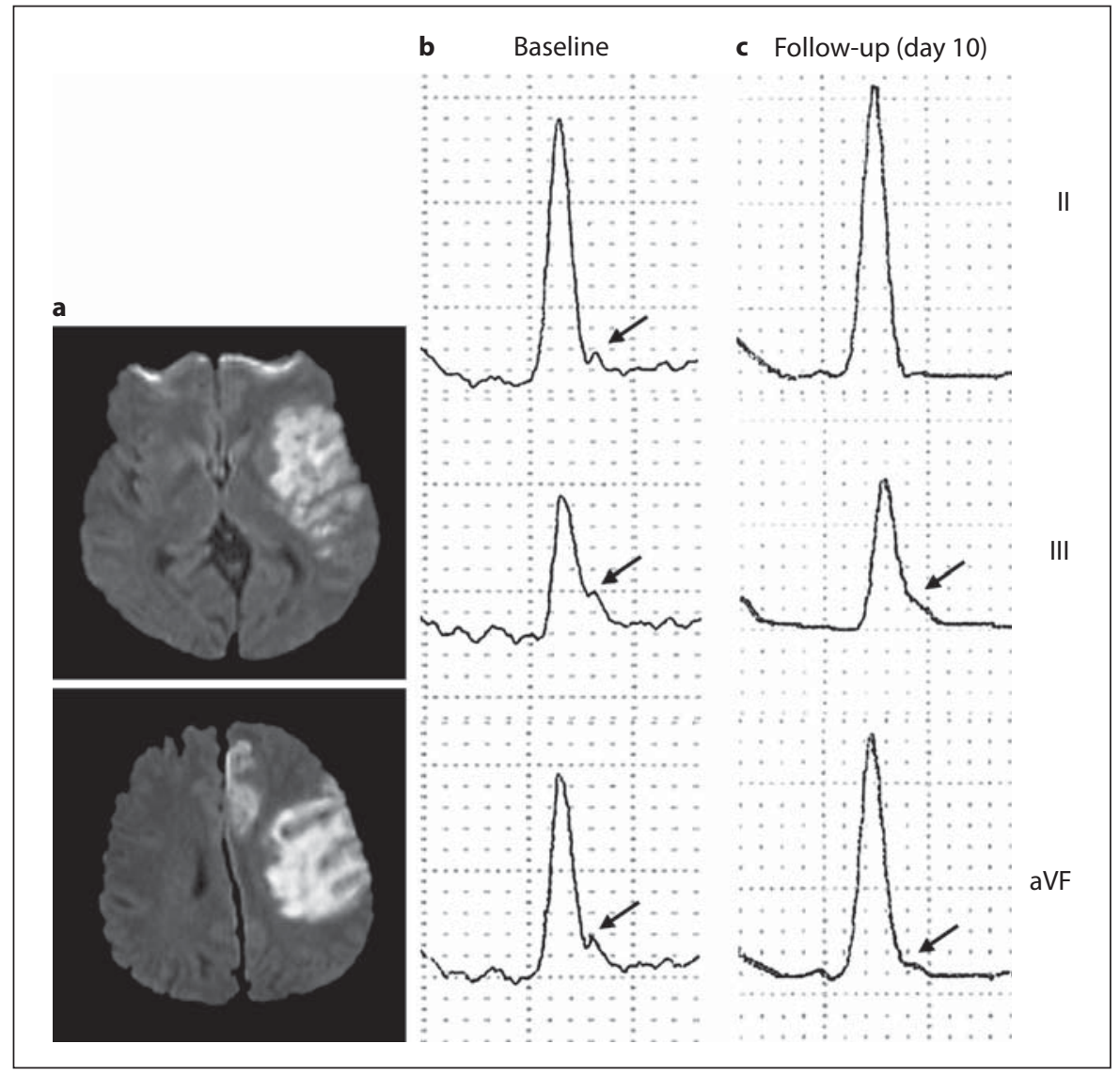

\section{KARGER}

Fax +41613061234 E-Mail karger@karger.ch www.karger.com
(2) 2011 S. Karger AG, Basel

1015-9770/11/0314-0414\$38.00/0

www.karger.com/ced 


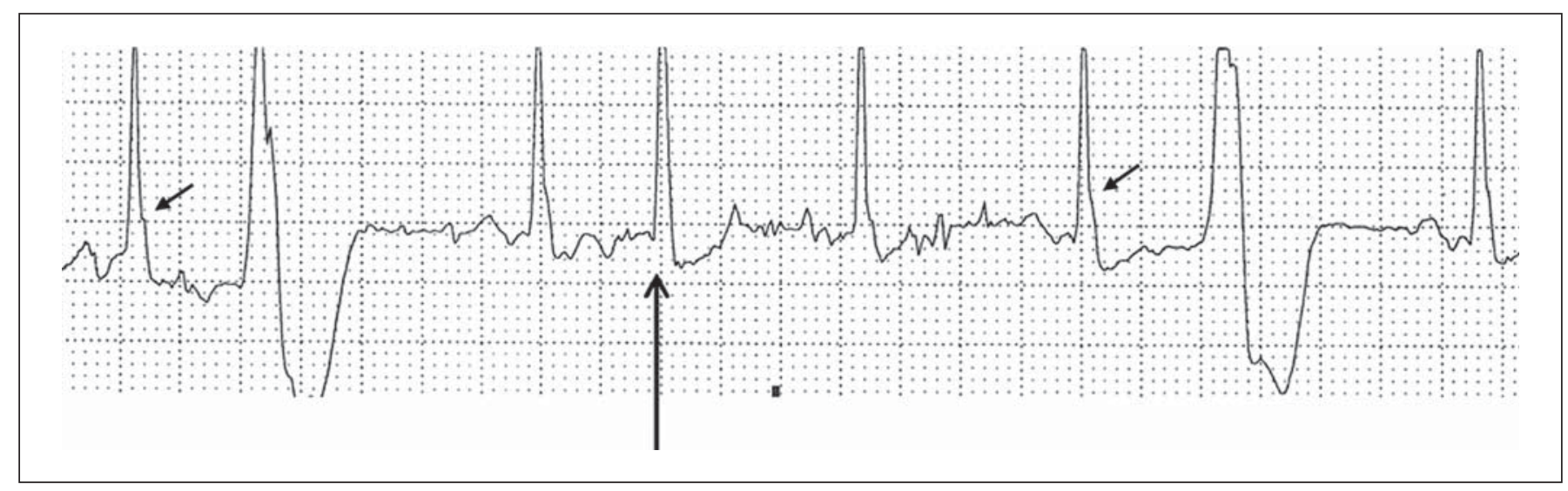

Fig. 2. Continuous cardiac monitoring showing regular beats with accentuated ER (small arrows) followed by premature ventricular complexes and scattered supraventricular premature beats (large arrow; heart rate: 95/min).

inferior leads (II, III, aVF) with J-point elevation of up to $0.19 \mathrm{mV}$ and notching at the end of the QRS complex was present (fig. 1). During cardiac monitoring for more than $72 \mathrm{~h}$ the patient had continuous sinus rhythm with recurrent premature ventricular complexes (fig. 2). On follow-up ECG recordings 10 days and 13 months later, ER changes were limited to leads III and aVF, had decreased in amplitude and changed the morphological pattern from notching to slurring (heart rate on day 10:50/min; online suppl. fig. 1, www.karger.com/doi/10.1159/000323611).

\section{Discussion}

ER, an elevation of the J-point with slurring or notching at the end of the QRS complex, was first described in 1936 [1]. For decades it has been considered a normal electrocardiographic variant without pathological impact [2,3]. Epidemiology studies estimate its prevalence to be about $5 \%$, with higher rates in males, people of black ethnicity and athletes [3]. It may be a transient finding with fluctuation of its morphological pattern and amplitude under various conditions [2-4]. It occurs more frequently in the context of physiological vagal activation with bradycardia [3], i.e. during sleep or after meals. An association with pathological conditions of autonomic imbalance, including spinal cord injuries [5] and attention deficit/hyperactivity disorder [6], is also reported. Recent investigations found an elevated risk of malignant ventricular arrhythmia [4], and in a community-based study the risk of death from any cause was significantly increased in subjects with ER $>0.2 \mathrm{mV}$ in the inferior leads [7].

Repolarization abnormalities on ECG are present in the majority of unselected patients with cerebral injury [8]. While many changes are caused by preexisting cardiac comorbidities, cerebral lesions at characteristic sites have been described to predispose to cardiac complications $[9,10]$. Affection of the left insular cortex, as reported in the present case, was shown to perturb cardiac autonomic tone in humans [10]. Therefore it is feasible that autonomic imbalance after stroke contributed to the ER changes and their diminishment with time. More systemic research is needed to evaluate whether a linkage connects early repolarization with autonomic disturbance after cerebral injury. Our observation may help to initiate such research.

\section{References}

1 Shipley RA, Hallaran WR: The four lead electrocardiogram in 200 nor mal men and women. Am Heart J 1936;11:325-335.

2 Klatsky AL, Oehm R, Cooper RA, Udaltsova N, Armstrong MA: The early repolarization normal variant electrocardiogram: correlates and consequences. Am J Med 2003;115:171-177.

- 3 Mehta M, Jain AC, Mehta A: Early repolarization. Clin Cardiol 1999; 22:59-65.

4 Haissaguerre M, Derval N, Sacher F, Jesel L, Deisenhofer I, de Roy L, Pasquie JL, Nogami A, Babuty D, Yli-Mayry S, De Chillou C, Scanu P, Mabo P, Matsuo S, Probst V, Le Scouarnec S, Defaye P, Schlaepfer J, Rostock T, Lacroix D, Lamaison D, Lavergne T, Aizawa Y, Englund A, Anselme F, O'Neill M, Hocini M, Lim KT, Knecht S, Veenhuyzen GD, Bordachar P, Chauvin M, Jais P, Coureau G, Chene G, Klein GJ, Clementy J: Sudden cardiac arrest associated with early repolarization. N Engl J Med 2008;358:2016-2023.

5 Lehmann KG, Shandling AH, Yusi AU, Froelicher VF: Altered ventricular repolarization in central sympathetic dysfunction associated with spinal cord injury. Am J Cardiol 1989;63:1498-1504.

-6 Nahshoni E, Sclarovsky S, Spitzer S, Zalsman G, Strasberg B, Weizman A: Early repolarization in young children with attention-deficit/hyperactivity disorder versus normal controls: a retrospective preliminary chart review study. J Child Adolesc Psychopharmacol 2009;19:731-735.

-7 Tikkanen JT, Anttonen O, Junttila MJ, Aro AL, Kerola T, Rissanen HA, Reunanen A, Huikuri HV: Long-term outcome associated with early repolarization on electrocardiography. N Engl J Med 2009;361:25292537.

$\checkmark 8$ Khechinashvili G, Asplund K: Electrocardiographic changes in patients with acute stroke: a systematic review. Cerebrovasc Dis 2002;14: 67-76.

-9 Klingelhofer J, Sander D: Cardiovascular consequences of clinical stroke. Baillieres Clin Neurol 1997;6:309-335.

10 Oppenheimer SM, Kedem G, Martin WM: Left-insular cortex lesions perturb cardiac autonomic tone in humans. Clin Auton Res 1996;6: 131-140.

Bernd Kallmünzer, MD

Department of Neurology, University Medical Center Erlangen Schwabachanlage 6

DE-91054 Erlangen (Germany)

Tel. +4991318544634

E-Mail bernd.kallmuenzer@uk-erlangen.de 